\title{
Spatial analysis and model construction of NDVI Based on meteorological data
}

\author{
Jifeng Wu, and Yayu Cheng* \\ School of Surveying and Mapping Science and technology, Xi'an University of science and \\ technology ,710000, Xi'an, Shaanxi, China
}

\begin{abstract}
NDVI (Normalized Vegetation Index) is an important characteristic index to study regional vegetation change, which is greatly influenced by meteorological data. Based on the analysis of the trend change and correlation between NDVI and PWV (Precipitable Water Vapor), precipitation and temperature in four geographical regions of China, this paper constructs a model between NDVI and PWV, precipitation and temperature in each geographical region according to multiple regression, and predicts NDVI through meteorological data. The results show that:(1) NDVI and meteorological factors have the same changing trend, and the maximum value appears in every region from June to September, and the value of NDVI in southern region is relatively large. (2) The correlation between rainfall and NDVI is the highest in Qinghai-Tibet region, the correlation between temperature, PWV and NDVI is the highest in northern region, the correlation between NDVI and rainfall, temperature and PWV is the lowest in southern region. (3)According to the meteorological data ,NDVI prediction can be achieved better, and the prediction effect in southern region is the best and the model accuracy is the highest. (4) NDVI is negatively related to El Niño event, positively related to La Nina event, and the stronger El Niño and La Nina events are, the higher the correlation is.
\end{abstract}

Keywords: Normalized vegetation index, Meteorological data, Spatial analysis, Multiple regression.

\section{Introduction}

Climate change is considered to be the main cause of land cover change, which is the focus of global change research [1]. The NDVI (Normalized Vegetation Index) is considered to be the best indicator factor of vegetation growth and vegetation coverage and the most effective indicator of monitoring area or global vegetation and ecological changes [2]. Many scholars have studied the relationship, sensitivity and change between climate factors (mainly precipitation, temperature) and NDVI from different angles, and discussed the mechanism of this relationship and its ecological effect [3].

\footnotetext{
*Corresponding author : 2728578494@,qq.com
} 
Scholars at home and abroad have done a lot of research on the relationship between time series NDVI data and meteorological factors, which proves that NDVI is sensitive to the response of meteorological factors [4]. Precipitation and air temperature are two important meteorological factors influencing the dynamic change of surface vegetation [5]: precipitation increases the soil moisture and provides water for vegetation growth; the increase of air temperature is conducive to the decomposition of organic matter and the increase of soil nutrient content, and at the same time, it can effectively improve the photosynthesis efficiency of vegetation, making NDVI rise. But the response of vegetation to climate change is still unclear. Most of the studies focus on the change pattern of NDVI space and the relationship between NDVI and meteorological factors [6]. However, the relationship between seasonal NDVI and meteorological factors and the response and lag of different vegetation types to meteorological factors are relatively few. Moreover, most scholars only select a small area as the main research object when analyzing the response of NDVI and meteorological factors, so the research content is only suitable for the small area.

In this paper, four geographical regions in China are selected as the main research areas, and NDVI prediction models for each region are established. Firstly, the change trends of NDVI, PWV, rainfall and temperature from 1982 to 2015 are analyzed, and the change dynamics in each region are explored. Secondly, the correlation between NDVI and PWV, rainfall and temperature is analyzed, and then the prediction model based on PWV, rainfall and temperature are established according to multiple regression model. Finally, a simple application of the predicted NDVI explore its response to ENSO (El Nino- Southern Oscillation) events.

\section{Summary of study area and data source}

\subsection{Summary of study area}

This paper mainly studies the Chinese mainland regions. As China is a vast region, with features of east, west, south, north and south, and the overall geographical trend is relatively complex, this paper mainly discusses according to the four geographical regions of China (i.e. the north region, the south region, the northwest region and the Qinghai-Tibet region). In terms of climate, the four geographical regions are temperate monsoon climate, subtropical monsoon climate, temperate continental climate and plateau mountain climate; In terms of precipitation, the annual precipitation in the south is more than $800 \mathrm{~mm}$, while that in the northwest is only less than $400 \mathrm{~mm}$, that is, the differences among the four geographical regions are different [7]. The meteorological factors and NDVI data at 693 meteorological station points in the Chinese mainland area are mainly selected in this paper, and the meteorological station distribution in Chinese mainland area is shown in Figure 1.

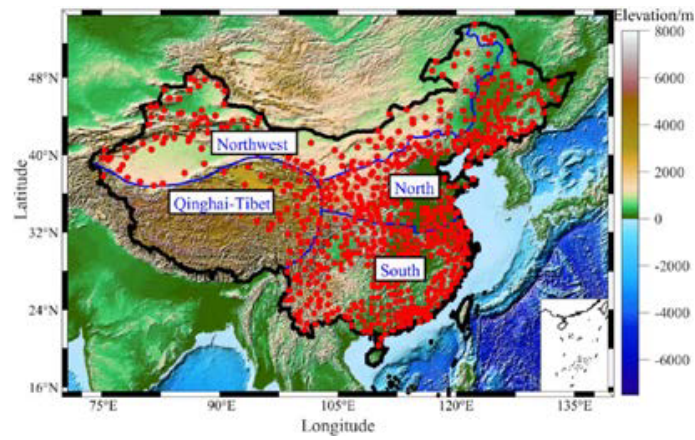

Fig. 1. Distribution of meteorological stations in four geographical regions of China. 


\subsection{Data description}

The NDVI data used in this article is GIMMSNDVI3g from the Global Monitoring and Model Research Group (GIMMS). It can be obtained free of charge through the https:/ecocast.arc.nasa.gov/data/pub/gimms/. The spatial scale covers the whole world. The temporal scale starts from 1981 to 2015 . The spatial resolution is $8 \mathrm{~km}$ and the temporal resolution is 15 days. Currently, there are 2 versions V0 and V1 in NC format. The reason why the GIMMS NDVI data is used for evaluation is that the data may have certain deviation in space, but there is no deviation in the process of time change [8-9].

Meteorological factor data are obtained from the http://cdc.cma.gov.cn/ of China Meteorological Science Data Sharing Service Network. The meteorological factor data used in this paper are mainly the temperature and precipitation data. The required change map of temperature and precipitation in the middle continent can be obtained through the meteorological data network, and the PWV data mainly comes from the fourth generation data product era interim provided by ECMWF.

The Nino 3.4 data contained in NOAA-ESRL data is mainly used for ENSO data. The Nino 3.4 data is the long-time sequence value of monthly SST anomaly from 1950 to present. The data of Nino 3.4 mainly reflects the variation of abnormal SST in the East Pacific, and the East Pacific is close to China, so the influence of Chinese mainland ENSO event on climate can be studied through Nino 3.4 data, and the influence on vegetation can be indirectly reflected.

\section{Results analysis}

\subsection{Trend analysis of NDVI and meteorological factors}

NDVI can be used to detect vegetation growth state, vegetation coverage and eliminate partial radiation error. Temperature is one of the meteorological factors affecting NDVI change, so it is equally important to analyze the change of temperature. It can be seen in Figure 2 that the NDVI in each geographical region has a similar trend with the temperature, with the maximum value from June to September. NDVI values are relatively high in the north and south, and relatively low in the northwest and Qinghai Tibet Plateau. From the change trend of temperature, it can be found that the temperature in the south is more than $0{ }^{\circ} \mathrm{C}$ all year round, which is consistent with the actual situation. The temperature in the north, northwest and Qinghai Tibet Plateau is relatively low, and the maximum value also appears from June to September, which is consistent with the actual change.

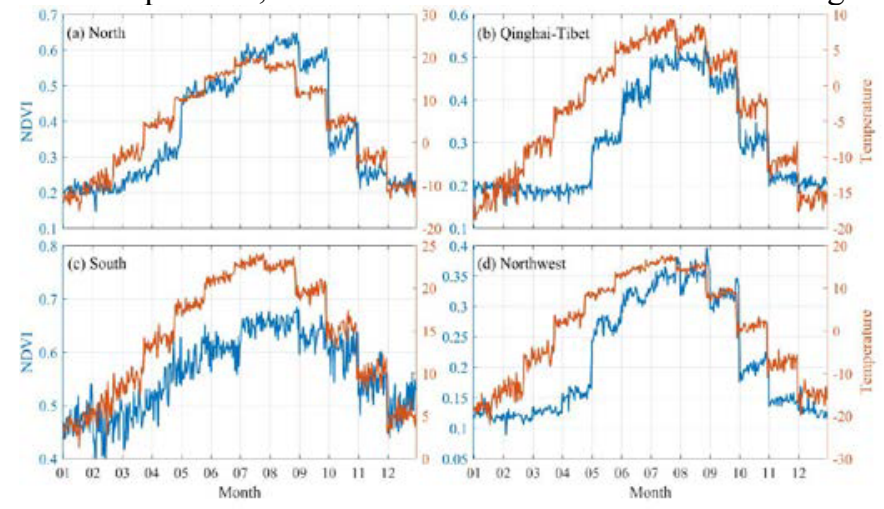

Fig. 2. NDVI and temperature change trend of four major geographical regions during 1982-2015. 
Besides the influence of temperature on NDVI, rainfall and PWV also play an important role, so it is equally important to analyze the variation trend of PWV and rainfall. PWV is precipitable water vapor and refers to the total amount of water vapor contained in the air column at unit face value [10]. Figure 3 shows the variation trend of PWV and rainfall in the four geographical regions over the period 1982-2015. It can be seen from the figure that the variation trend of PWV and rainfall is almost the same, among which the coincidence degree is higher in the southern region, and the variation trend is similar to that of NDVI, which is the maximum value in June to September. It is obvious from the figure that PWV and rainfall are the most in the southern region, and are relatively less in the northwest region and Qinghai-Tibet region. The maximum rainfall in South China can reach $300 \mathrm{~mm}$, while the maximum rainfall in Qinghai-Tibet and Northwest China can reach $150 \mathrm{~mm}$ and $80 \mathrm{~mm}$ respectively, which is consistent with the actual phenomenon. At the same time, it is consistent with the phenomenon that the NDVI value is relatively large in the southern region, so there is a certain relationship between NDVI and meteorological factors.

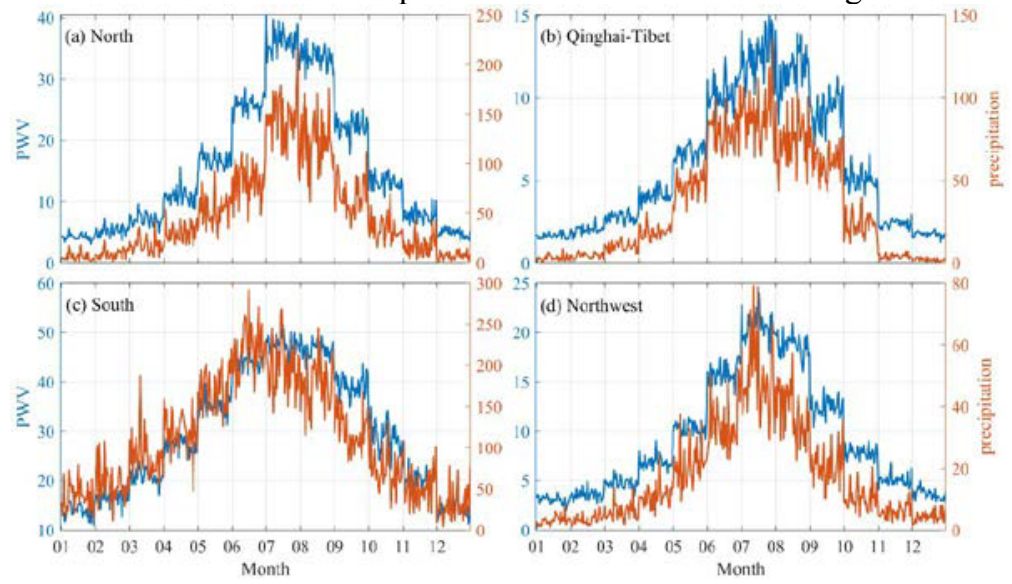

Fig. 3. The variation trend of PWV and rainfall in each month of the four geographical regions during 1982-2015.

\subsection{Correlation analysis of NDVI and meteorological factors}

In order to accurately analyze the correlation between NDVI and meteorology, the correlation between NDVI and rainfall, PWV and temperature in four geographical regions is calculated in this paper. Fig. 4 shows the correlation between NDVI and rainfall, PWV and temperature. It can be seen that NDVI is highly correlated with meteorological factors in most regions, and only some stations in the south of the south are relatively poor, which may be related to the perennial humidity and climate change in the south. Figure 5 gives a hot map of the correlation between NDVI and meteorological factors in four geographical regions. It can be clearly seen from the figure that in the four regions, NDVI has a high correlation with rainfall, PWV and air temperature, and the southern region is relatively poor, which has a direct relationship with the poor correlation of some stations in the southern region. Table 1 shows the average correlation between NDVI and meteorological factors in four geographical regions. It can be seen that the correlation between rainfall and NDVI is the highest in Qinghai-Tibet region, the correlation between temperature, PWV and NDVI is the highest in northern region, and the correlation between NDVI and rainfall, temperature and PWV is the lowest in southern region, which may be directly related to the influence of ENSO in southern region. 


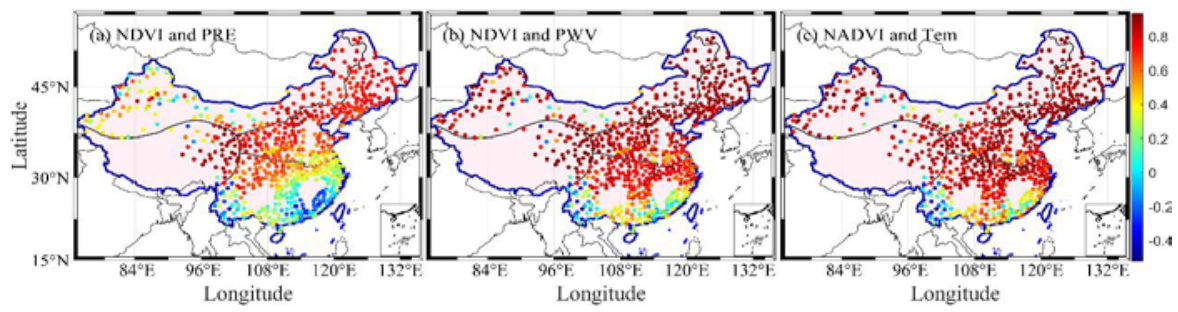

Fig. 4. Correlation of NDVI with rainfall, PWV and temperature in four geographical regions.
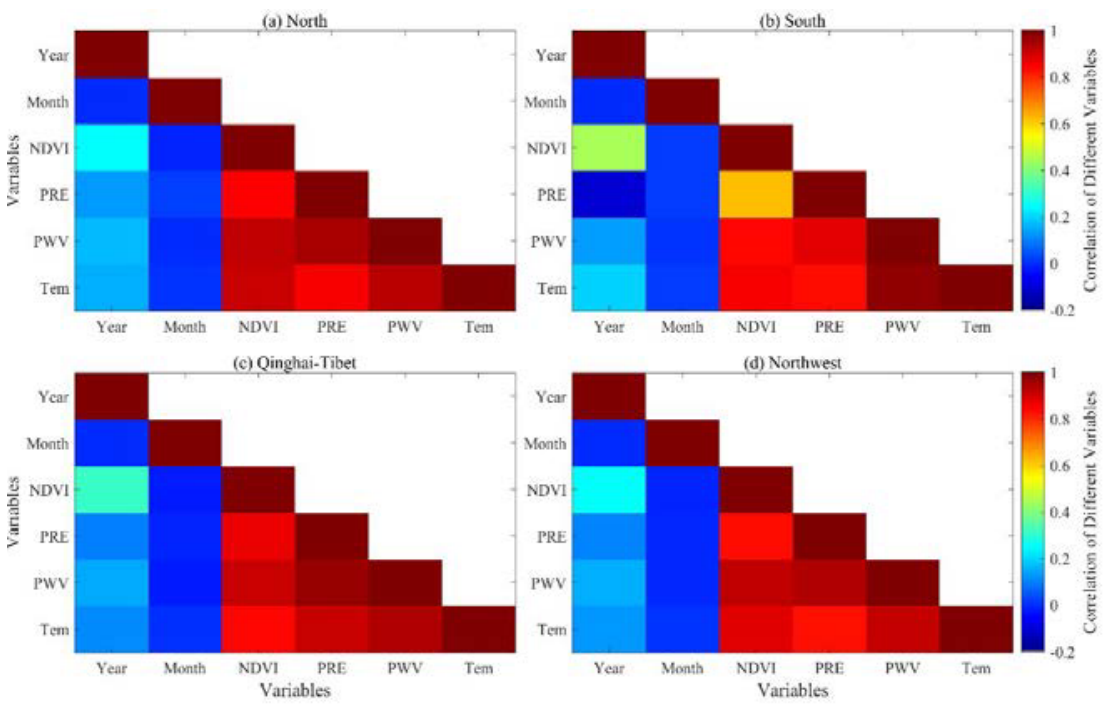

Fig. 5. Hot spot map of correlation among different variables in four geographical regions.

Table 1. Average correlation between NDVI and meteorological factors in four geographical regions.

\begin{tabular}{cccc}
\hline Geographical division & NDVI and rainfall & $\begin{array}{c}\text { NDVI and } \\
\text { temperature }\end{array}$ & NDVI and PWV \\
\hline Northern region & 0.64 & 0.85 & 0.85 \\
Southern region & 0.23 & 0.58 & 0.53 \\
Qinghai-Tibet region & 0.67 & 0.73 & 0.80 \\
Northwest region & 0.48 & 0.77 & 0.78 \\
\hline
\end{tabular}

\subsection{NDVI prediction model construction}

It can be seen from 3.2 that NDVI and meteorological factors have good correlation in each region. Therefore, NDVI prediction can be realized through multiple regression modeling according to meteorological factors. Specific expression is shown in Formula (1).

$$
\operatorname{NDVI}_{\text {forecast }}=\mathrm{a}_{0}+\mathrm{a}_{1} * P R E+\mathrm{a}_{2} * P W V+\mathrm{a}_{3} * \text { Tem }
$$

where, $N D V I_{\text {forecast }}$ is the predicted value of NDVI, $a_{0}, a_{1}, a_{2}, a_{3}$ are the ratio coefficients of constant and each factor respectively, PRE, PWV, Tem are meteorological factors. Among them, $\mathrm{a}$ and $\mathrm{b}$ are rainfall and temperature respectively. 
In order to clearly describe the degree of coincidence between the predicted NDVI value and the actual NDVI value according to the model, Fig.6 shows the long time series diagram of the predicted NDVI value and the actual NDVI value and their residuals in different regions. It can be seen from the figure that in each geographical division, the predicted value of NDVI is well fitted with the actual value, and the residual value of the two fluctuates around 0 , of which the fitting degree in the south is the highest, which may be related to the climate conditions in the south. In order to accurately know the prediction effect of NDVI, the RMS, Mae and MAPE indexes of the residual value between the predicted value and the actual value of NDVI in each geographical division are counted in Table 2. It can be seen from the table that the RMS index and MAE index are small in each geographical region, indicating that the difference between the predicted value and the actual value is small. Through the MAPE index, it can be concluded that the model has good prediction accuracy of NDVI, especially in the southern region.

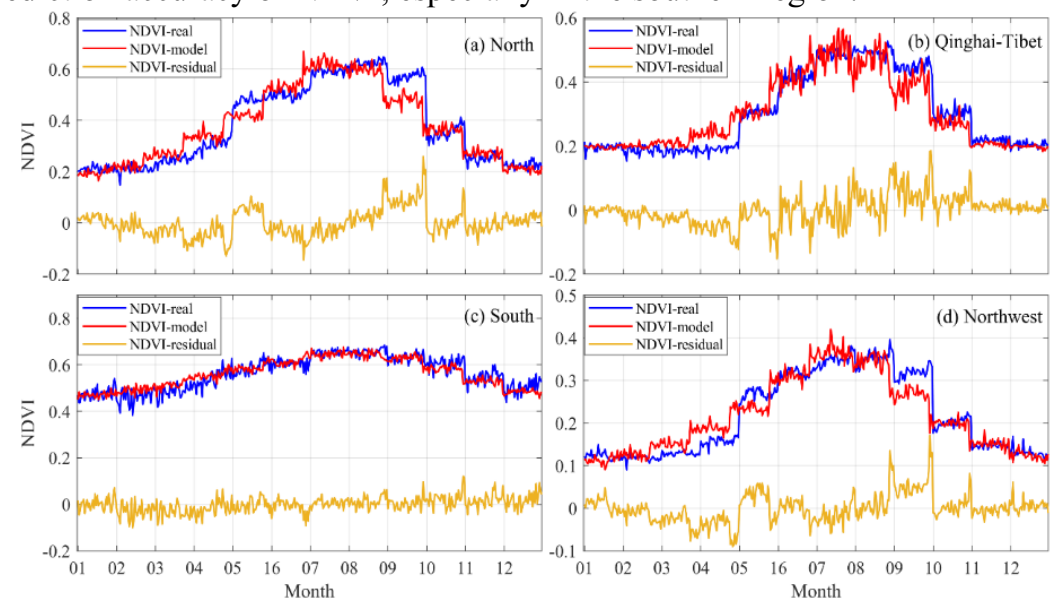

Fig. 6. Long time series variation of NDVI predicted value and actual value in each geographical region.

Table 2. Statistics of accuracy evaluation indexes of four geographical zoning models.

\begin{tabular}{cccc}
\hline Geographical division & RMS & MAE & MAPE \\
\hline Northern region & 0.05 & 0.04 & 11.32 \\
Southern region & 0.03 & 0.03 & 4.83 \\
Northwest region & 0.03 & 0.02 & 12.39 \\
Qinghai-Tibet region & 0.05 & 0.03 & 11.77 \\
\hline
\end{tabular}

\subsection{NDVI and ENSO event response}

Because the change of NDVI is affected by many factors, this paper briefly analyzes the influence of other factors except meteorological factors on NDVI, and mainly discusses the response of NDVI to ENSO by taking ENSO events as an example. Firstly, the change trend of Nino 3.4 in ENSO events from 1950 to 2018 is analyzed. ENSO personal leave mainly includes El Ni ñ O and La Ni ñ o. Secondly, the correlation degree of NDVI in El Nino year and La Nino year is analyzed by moving window analysis, so as to reflect the response of NDVI to El Nino and La Nino. Fig. 7 shows the change trend of ENSO during 1950-2018. It can be seen from the figure that the positive and negative change trends of nino3.4 are similar, and the change trend will be the largest in a period of time. This 
situation shows that the El Ni ñ o event is strongly reflected, so it also has a severe impact on temperature, rainfall and other meteorological factors during this period, This impact needs to be addressed through appropriate internal measures. Fig. 8 shows the long-time correlation diagram of NDVI and ENSO response. From the diagram, it can be seen that during El Ni ñ o years, the correlation coefficient between NDVI and ENSO tends to be between $-0.5 \sim 0.5$, and there are many El Ni ñ o events. Table 3 shows the El Ni $\tilde{n}$ o events from 1982 to 2015. According to figure 8 and table 3, the greater the intensity of El Ni ñ o events, the stronger the negative correlation with NDVI. Therefore, El Ni ñ o has an obvious impact on NDVI, and the overall intensity is also strong. Table 4 shows the La Nina events from 1982 to 2015. Combined with figure 8 and table 4 , the greater the intensity of La Nina events, the stronger the positive correlation with NDVI. Therefore, the greater the impact on NDVI during La Ni ñ o.

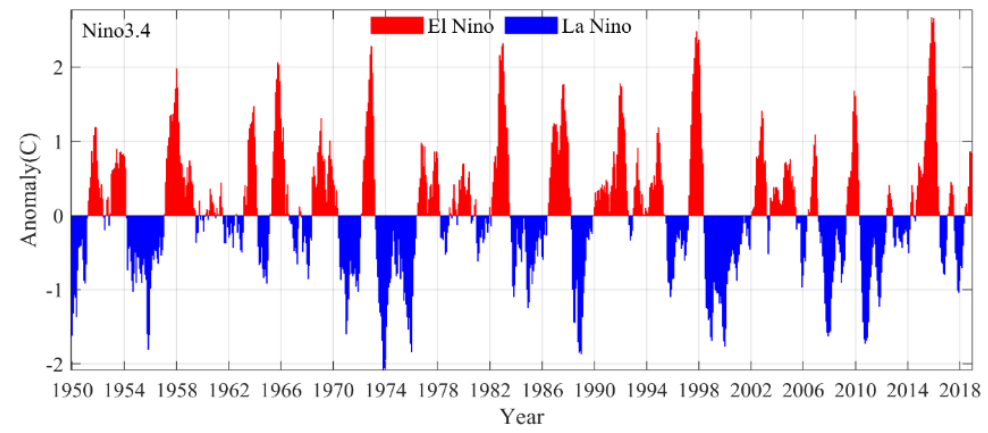

Fig.7. Trends of ENSO events during 2018-1950.

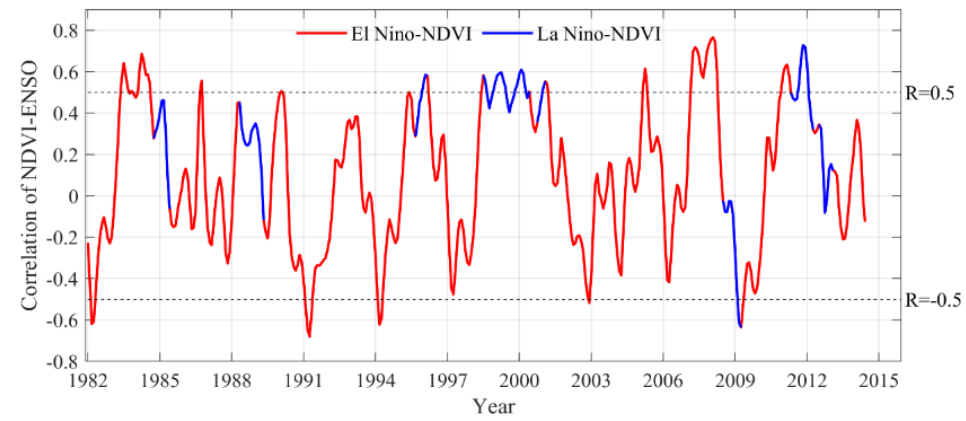

Fig. 8. Long time series of correlation between NDVI and ENSO events during 1982-2015.

\section{Discussion and conclusion}

\subsection{Discussion}

Through this study, it is found that the correlation between NDVI and meteorological factors is different in each geographical division, and the prediction of NDVI can be realized according to meteorological factors. In addition, this study shows that ENSO events have a certain impact on NDVI. In this paper, it is found that the correlation between NDVI and meteorological factors is low in the south, and this reason is not further analyzed 
in this paper. The preliminary discussion may be caused by the large impact of ENSO events in the south. Therefore, continuous exploration is still needed to solve this problem. In addition, for the construction of NDVI prediction model, this paper only selects three meteorological factors: rainfall, temperature and PWV. Other factors should be added in the follow-up to accurately build the NDVI prediction model. Because the accuracy of multiple regression model is relatively low, the future research should consider introducing machine learning to improve the accuracy of the model and realize the real-time prediction of NDVI.

Table 3. El Niño events during 1982-2015.

\begin{tabular}{|c|c|c|c|c|c|c|c|}
\hline $\begin{array}{l}\text { Serial } \\
\text { number }\end{array}$ & $\begin{array}{c}\text { Start and end } \\
\text { date }\end{array}$ & $\begin{array}{l}\text { Lengt } \\
\mathrm{h} / \\
\text { mon }\end{array}$ & $\begin{array}{l}\text { Peak } \\
\text { time }\end{array}$ & $\begin{array}{l}\text { Peak } \\
\text { season }\end{array}$ & $\begin{array}{c}\text { Peak } \\
\text { intensity } \\
/{ }^{\circ} \mathrm{C}\end{array}$ & $\begin{array}{l}\text { Strength } \\
\text { grade }\end{array}$ & $\begin{array}{l}\text { Event } \\
\text { type }\end{array}$ \\
\hline 1 & $\begin{array}{c}1982.04-1983 . \\
06\end{array}$ & 15 & 1983.01 & Winter & 2.7 & $\begin{array}{c}\text { Super } \\
\text { strong }\end{array}$ & $\begin{array}{c}\text { Eastern } \\
\text { type }\end{array}$ \\
\hline 2 & $\begin{array}{c}1986.08-1988 . \\
02\end{array}$ & 19 & 1987.08 & Summer & 1.9 & Secondary & $\begin{array}{l}\text { Eastern } \\
\text { type }\end{array}$ \\
\hline 3 & $\begin{array}{c}1991.05-1992 . \\
06\end{array}$ & 14 & 1992.01 & Winter & 1.9 & Secondary & $\begin{array}{l}\text { Eastern } \\
\text { type }\end{array}$ \\
\hline 4 & $\begin{array}{c}1994.09-1995 . \\
03\end{array}$ & 7 & 1994.12 & Winter & 1.3 & Secondary & $\begin{array}{l}\text { Middle } \\
\text { type }\end{array}$ \\
\hline 5 & $\begin{array}{c}1997.04-1998 . \\
04\end{array}$ & 13 & 1997.11 & Autumn & 2.7 & $\begin{array}{l}\text { Super } \\
\text { strong }\end{array}$ & $\begin{array}{l}\text { Eastern } \\
\text { type }\end{array}$ \\
\hline 6 & $\begin{array}{c}2002.05-2003 . \\
03\end{array}$ & 11 & 2002.11 & Autumn & 1.6 & Secondary & $\begin{array}{l}\text { Middle } \\
\text { type }\end{array}$ \\
\hline 7 & $\begin{array}{c}2004.07-2005 . \\
01\end{array}$ & 7 & 2004.09 & Autumn & 0.8 & Weak & $\begin{array}{l}\text { Middle } \\
\text { type }\end{array}$ \\
\hline 8 & $\begin{array}{c}2006.08-2007 . \\
01\end{array}$ & 6 & 2006.11 & Autumn & 1.1 & Weak & $\begin{array}{l}\text { Eastern } \\
\text { type }\end{array}$ \\
\hline 9 & $\begin{array}{c}2009.06-2010 . \\
04\end{array}$ & 11 & 2009.12 & Winter & 1.7 & Secondary & $\begin{array}{l}\text { Middle } \\
\text { type }\end{array}$ \\
\hline 10 & $\begin{array}{c}2014.10-2016 . \\
04\end{array}$ & 19 & 2015.12 & Winter & 2.8 & $\begin{array}{l}\text { Super } \\
\text { strong }\end{array}$ & $\begin{array}{c}\text { Eastern } \\
\text { type }\end{array}$ \\
\hline
\end{tabular}

Table 4. La Niño incident during 1982-2015.

\begin{tabular}{|c|c|c|c|c|c|c|c|}
\hline $\begin{array}{c}\text { Serial } \\
\text { number }\end{array}$ & $\begin{array}{c}\text { Start and end } \\
\text { date }\end{array}$ & $\begin{array}{l}\text { Length } \\
\text { /mon }\end{array}$ & $\begin{array}{l}\text { Peak } \\
\text { time }\end{array}$ & $\begin{array}{l}\text { Peak } \\
\text { season }\end{array}$ & $\begin{array}{c}\text { Peak } \\
\text { intensity } \\
/{ }^{\circ} \mathrm{C}\end{array}$ & $\begin{array}{l}\text { Strength } \\
\text { grade }\end{array}$ & $\begin{array}{l}\text { Event } \\
\text { type }\end{array}$ \\
\hline 1 & $1984.10-1985.06$ & 9 & 1985.01 & Winter & -1.2 & Weak & $\begin{array}{c}\text { Eastern } \\
\text { type }\end{array}$ \\
\hline 2 & 1988.05-1989.05 & 13 & 1988.12 & Winter & -2.1 & Strong & $\begin{array}{l}\text { Eastern } \\
\text { type }\end{array}$ \\
\hline 3 & $1995.09-1996.03$ & 7 & 1995.11 & Autumn & -0.9 & Weak & $\begin{array}{c}\text { Eastern } \\
\text { type }\end{array}$ \\
\hline 4 & $1998.07-2000.06$ & 24 & 2000.01 & Winter & -1.6 & Secondary & $\begin{array}{c}\text { Eastern } \\
\text { type }\end{array}$ \\
\hline 5 & $2000.10-2001.02$ & 5 & 2000.12 & Winter & -0.8 & Weak & $\begin{array}{l}\text { Middle } \\
\text { type }\end{array}$ \\
\hline 6 & $2007.08-2008.05$ & 10 & 2008.01 & Winter & -1.7 & Secondary & $\begin{array}{c}\text { Eastern } \\
\text { type }\end{array}$ \\
\hline 7 & 2010.06-2011.05 & 12 & 2010.12 & Winter & -1.6 & Secondary & $\begin{array}{c}\text { Eastern } \\
\text { type }\end{array}$ \\
\hline 8 & $2011.08-2012.03$ & 8 & 2011.12 & Winter & -1.1 & Weak & $\begin{array}{l}\text { Middle } \\
\text { type }\end{array}$ \\
\hline
\end{tabular}




\subsection{Conclusion}

This paper first discusses the change trend of NDVI, rainfall, temperature and PWV according to the four geographical divisions of China, then analyzes the correlation between NDVI and the above meteorological factors, finally constructs the NDVI prediction model based on rainfall, temperature and PWV, and compares the predicted value of NDVI with the actual value to evaluate the accuracy of the model. Finally, the response of ENSO event to NDVI is discussed. The main conclusions are as follows:

According to the trend changes of NDVI, temperature, rainfall and PWV, it is found that the maximum value appears from June to September, and NDVI has the same change trend with meteorological factors, among which the NDVI value in southern China is relatively large.

By exploring the correlation between NDVI and meteorological factors, it is found that the correlation between rainfall and NDVI is the highest in Qinghai Tibet, the correlation between temperature, PWV and NDVI is the highest in the north, and the correlation between NDVI and rainfall, temperature and PWV is the lowest in the south.

By establishing the NDVI prediction model of each region, it is found that the NDVI prediction can be better realized according to the meteorological data, among which the prediction effect of the south region is the best and the model accuracy is the highest.

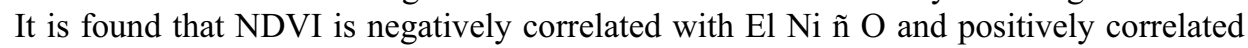
with La Ni ñ o, and the stronger the intensity of El Nino and La Nina events, the higher the correlation.

Thanks to the data provided by the global monitoring and model research group, China Meteorological science data sharing service network and noaa-esrl. This work is supported by Scientific Research Plan Projects of Shaanxi Education Department (CN), grand number:20JK0776.

\section{References}

1. Yunhao Chen, Xiaobing Li, Peijun Shi. 2001. Variation in NDVI driven by climate factors across China in 1983 1992. Acta Phytoecol Sin, 25 (6) :716 720.

2. Baofa Peng, Duanlu Chen, Wenjun LI, et al. Stability of Landscape Pattern of Land Use: A Case Study of Changde[J]. SCIENTIA GEOGRAPHICA SINICA, 2013, 33(12): 1484-1488.

3. Rodrigues A, Marçal A R S, Cunha M. Identification of potential land cover changes on a continental scale using NDVI time-series from SPOT VEGETATION[J]. International journal of remote sensing, 2013, 34(22): 8028-8050.

4. Shuhua Qi , Changyao Wang, Zheng Niu ,et al. SVI and VCI based on NDVI Times-Series dataset used to monitor vegetation growth status and its response to climate variables[J]. Progress in geography, 2004, 23(3): 91-99.

5. Daoyi Gong, Peijun Shi, Xuezhao He . Spatial features of the coupling between the northern hemispheric NDVI and temperature in spring[J].Acta GeographicaSinica, 2002, 57(5): 505-514.

6. Xingkui $\mathrm{Xu}$, Zhaohui Lin, Feng Xue, et al. Correlation analysis between meteorological factors and vegetation growth[J].Acta EcologicaSinica, 2003, 23(2): 221-230.

7. La Ba, La Zhen, Zhuo Ga. NDVI change and its response to climate change in Nag Qu city during 2000-2018[J]. Mountain Research, 2019, 37(4): 499-507.

8. Qin Wang . Variation characteristics of NDVI and its response to meteorological factors in Fujian Province[D]. Fujian Agriculture and Forestry University,2015. 
9. Ruimei Han , Pei Liu, Chao Ma, et al. NDVI3g trend and its response to climate change in ordos during period from 1982 to 2012[J]. Bulletin of soil and water conservation, 2016: 28-33, 39.

10. Yuchun Xiang, Zhenghong Chen, Guirong Xu, et al. Comparison and analysis of the results of three Atmospheric Precipitable Water Calculation Methods[J]. meteorological, 2009, 35(11): 48-5 